\title{
for(e)dialogue
}

Department of Media and Communication

Volume 1, Issue 1: New Directions in Media Research 2015

"Here you can use it": Understanding mobile phone sharing and the concerns it elicits in rural Kenya

Leah Komen

(p. 52-65)

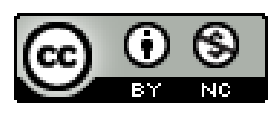

This work is licensed under a

Creative Commons Attribution- Non Commercial 4.0 International License

March 2016 
Volume 1, Issue 1: New Directions in Media Research 2015

\section{"Here you can use it": Understanding mobile phone sharing and the concerns it elicits in rural Kenya}

\section{Leah Komen}

Abstract: Globally, mobile phones are mostly used as personal items largely due to their data storage and services provision. However, various features enable mobile phone sharing and this subverts the notion of a single individual use. In cultures where communal sharing is valued and seen as normal, it is natural for mobile phones to be incorporated into other traditionally shared support systems, such as meetings summoned by elders, which involve social, economic, cultural and political activities. This paper draws on a recent doctoral thesis to examine the role of mobile telephony in the social transformation and development of Marakwet, a sub-ethnic group of the Kalenjin community in the Rift Valley region of western Kenya. The paper argues that the adoption and domestication of mobile telephony is both innovative and a source of problems for the Marakwet, depending on how the device is used in everyday life. The paper shows that while mobile phone sharing amongst the Marakwet is the most preferred practice, privacy and data security are key concerns among users.

Keywords: Mobile telephony, assemblage, sharing, privacy and security concerns.

\section{Introduction}

Mobile phones are generally thought of as personal items. However, there are contexts whereby the device is shared by various users, subverting the above owner-consumer narrative. Various mobile phone features enable users to frequently share the device and its functions with others. In cultures where communal sharing is valued and viewed as normal, mobile phones are usually incorporated into other shared support systems, such as meetings summoned by elders. Generally, communal mobile phone use is an arrangement whereby the device is accessible to multiple users, typically in a public space. This access is either free or attracts a small affordable fee.

Mobile phone sharing is common in developing countries, though there are insufficient empirical studies on this phenomenon. This mobile phone sharing practice has been defined "informal, non-numerative, resource distributing activity where multiple individuals have a relationship with a single device - as purchasers, owners, possessors, operators and/or users" (Burell, 2010, p.230). This implies that an original holder grants to others the partial use, enjoyment or possession of an item, resource or place. However, such a definition is not exhaustive, and is challenged and problematized by emergent methods of sharing, be they formal (that is, with strict agreement reached) or informal (based on trust). This raises questions about the nature of the much 
Volume 1, Issue 1: New Directions in Media Research 2015

debated interactions between mobile phone users and the device itself. This paper thus examines ideas about mobile phone sharing, sharing patterns and trust and mischief assemblages as issues of critical concern in the daily life of the Marakwet people in western Kenya.

Sharing is a key subject in social inquiry (Mauss, 1990; Huntsman and Hooper, 1996). Mobile telephony has also been the centre of media research in developed countries, where it is celebrated for its multiple uses as a personal device (Ling, 2004; Ito et al., 2005; Livingstone, 2002). But in developing countries, research on mobile phone sharing is relatively limited, although sharing of the device is widely acknowledged as a common practice in those countries. A report by United Nations Conference on trade and Development (UNCTAD) avers this fact, stating that in developing countries, especially in poor, rural communities, several people frequently shared a single mobile phone (UNCTAD,2005,P. 12). A study of urban teens in Sweden by Weilemann and Larsson (2001) demonstrated the social character of mobile phone sharing and how this challenges the conventional view of mobile telephones as distinctively personal devices. For Katz and Aakhus (2002), Swedish urban teens share phones 'minimally' by exchanging messages across handsets and sharing time through borrowing and lending phones. In their study, Steenson and Donner (2008) established that in urban Indian families' individuals and friends often share one or more mobile phones, a practice largely motivated by social obligation, familial customs and traditional gender roles.

The sharing of mobile telephony is also common in parts of Africa (Vodafone, 2005), for instance, in rural Rwanda, where handsets are often used by several individuals (Donner, 2005, P. 2). Similar experience is evident in Burkina Faso, where many villagers share a single phone (Hans and Kibora, 2008). Carmody (2010) attributes this practice to the huge costs of mobile phones and the large numbers of phone subscribers in Africa.

\section{Theorising mobile phone sharing assemblage}

Science and Technology scholarship argues that the relationship between the users and technological devices is an interrelation that does not privilege one over another. But Lucy Suchman, (2007) proposes a more inclusive understanding of human-machine interactions that acknowledges the actual realities of the complexities of such interactions. Following the Actor-Network theory (ANT) of Callon (1986) and Latour (2005), Suchman proposes an approach that promotes intraactions', whereby boundaries between humans and machines are produced, disrupted and transgressed (2007, p.256). For instance, when people share their mobile phones, they tend to create boundaries between who is admitted or not admitted. However, sharing also leaves room for 
Volume 1, Issue 1: New Directions in Media Research 2015

the inclusion of others, especially during emergencies, whereby such individuals are seeking urgent help from other people. In effect, by looking at the co-production of humans and machines as an effect of fields of intra-action, a new view of the human will also emerge. In this way, humanmachine interactions become dynamic, rather than static.

Mobile phone sharing is also informed by norms of reciprocity (Donner and Steenson, 2008; Ling and Donner, 2009), as individuals who refuse to share can be considered as selfish and flouting the local convention. However, a person who has been robbed of their phone or defrauded with a phone may be reluctant to share the device, regardless of societal norm. Sharing, therefore, reveals the complexity of human-machine interactions, and such relationships can best be explained by observing and explaining them within their specific contexts.

The assemblage theory provides a powerful basis to better grasp mobile phone sharing. Manuel DeLanda (2006) explains that this theory considers heterogeneous components that interact to form a whole through performing several roles and processes that describe the identity of an assemblage. This identity is not fixed but changes as components perform roles that transform them into other assemblage in a process of relations of exteriority. Assemblage theory thus goes beyond explaining the tensions between humans and mobile telephony to also allow for the emergence of new identities of assemblages as this interaction goes on. In effect, the Assemblage theory concerns how various components that make up sharing assemblage constantly interact to form new assemblages.

According to DeLanda (2006), the components of a social assemblage play varying material roles. The material components include: the mobile phone device itself; gender roles in terms of access and the expectations of society regarding sharing, such as requests for physical assistance, for instance, one phone user calling another to ask them to take care of their children, to purchase stuff from the market, or to rescue them from some ugly situations. Other material components of the assemblage include: the amount of time, energy and devotion invested in building and sustaining mutual relationships, and the people exchanging conversations around sharing, and who could converse in physical proximity or from afar. In contrast, expressive roles transcend language and symbols to include decisions made before actual encounters, the motivation behind sharing, and decisions on whether to share time, money and/or chores, and manner of bodily expressions (DeLanda, 2006: 12).

In Marakwet, sharing assemblages have the following distinctive expressive components: 
Volume 1, Issue 1: New Directions in Media Research 2015

- the non-linguistic display of solidarity, cohesiveness and trust, for example, manner of greeting and type of posture, with proximity depicting closeness of relationship;

- particular Marakwet dialects spoken, which identify individuals' community membership;

- interpersonal networks among peers and within the community

- Certain cultural practices that include preferred areas for meetings, communal meeting places, choice of times and length of meetings, etc.

\section{Methodology}

The study was purely qualitative, involving 12 households in Sibou Village of the Marakwet district. Using ethnographic interviews and field notes as the key methods of data collection, supplementary data was generated from 5 focus group discussions conducted among discrete social groups, namely: women; men and women together; clan leaders; teenage girls; and boys. The purpose was to generally understand the use and consumption of mobile telephony in both the household and the family. The focus groups were structured against the backdrop that the community operates mostly in social networks groups. The same questions were asked in the focus groups and the ethnographic interviews to make comparisons across the diverse participants possible. Questions were designed to elicit open-ended responses from three broad and sometimes overlapping areas, namely:

- descriptions of personal mobile phone use patterns and preference by individual household members;

- perceptions on the societal use and implications of mobile phones among various (socioeconomic) status groups

- opinions on how mobile phones can benefit the community better.

Ten of the participating households were adopters who had access to and used mobile telephony, while two households were non-adopters, chosen to draw comparisons on the motivations for the use and non-use of mobile phones. Literate participants gave their consent by signing a consent form, whereas the semi-literate gave a verbal consent, which was audio-recorded. Participants were given pseudonyms to protect their identity. Also, they were encouraged to describe their personal encounters with mobile phones, so as to determine the different shades of their experiences with the devices. 
Volume 1, Issue 1: New Directions in Media Research 2015

\section{Findings and discussions}

The study showed that amongst teenagers, sharing was motivated by friendship and the need to share costs. One was not expected to share without contributing in some way. For instance, Boaz, aged 19, explained how he contributed towards his friends' mobile phones, to enable him use them to call his girlfriend or listen to radio broadcasts:

I do not have to worry, because I don't own a mobile phone, all I need to do is give the owner twenty bob (twenty Kenya shillings) to charge his phone or twenty bamba (twenty Kenya shillings ) for top-up; then I can come along and we listen to news together with other friends. So it is not a must to own a phone; we just do cost sharing.

Yet another respondent Cheptoo, aged 18, stated:

For us girls we do not have that much money, but what we do is agree to top up one phone and each can text to their boyfriend or whoever and another can decide to pay for the phone charging and then we can save the texts under different files, so that one can feel a sense of privacy.

These two accounts illustrate how actions in this community depend largely upon circumstances, needs and desire to communicate, which are rooted in the act of cost sharing and reciprocity. Individuals are motivated by a lack of phones, and teenagers do not consider this as an impediment to their ability to communicate with significant others. They see it as an opportunity for socialisation even as they go about their individual lives. This is typical of assemblage theory, as it does not embrace a single logic. To several others mobile sharing territorialises, de-territorialise, or reterritorialise, which Suchman describes as the transgression of boundaries (2007). Sharing among teenagers includes, but is not limited to: sending short message texts (SMS); emailing others with internet enabled phones; making calls; sending and receiving money through their mobile phones, a service known as M-PESA; listening to news and listening to music, especially among boys.

\subsection{Mobile phone sharing patterns}

Activities relating to mobile phone sharing went on regardless of what gender owned or had access to the device, be they temporary custodians of the borrowed phone, or a friend of a friend. This then raises the critical question of whether or not technology is gender neutral.

When individuals interact through mobile phone sharing, they not only display their preferences as to whom they ask favours from, but this choice implies aspects of their personalities, 
Volume 1, Issue 1: New Directions in Media Research 2015

that is, what they like; who they like to hang out with; who they prefer and what their tastes are like. For instance, two people might have identical mobile phones with the same amount of credit and those who do not own mobile phones will make a choice as to who they will borrow the phone from. It is very likely that factors, such as the attitude of the phone owner towards the potential borrower, the relationship between the owner and the non-owner, experiences in the past and matters of trust, will affect who the person without a mobile phone chooses to borrow the device from. In other words, a "mobile phone is not only a symbolic repository for the user's social capital but also signals to others certain unspoken clues about the user's identity and social status" (Larsson, 2009, p. 9).

Mobile phone sharing practices are diverse and vary among individuals. However, some participants preferred some practices to others. Some practices relate to those held in the preownership culture, where many depended on a few who had communication technologies like radio and television to meet the information they need.

\section{Mobile Phone sharing patterns}

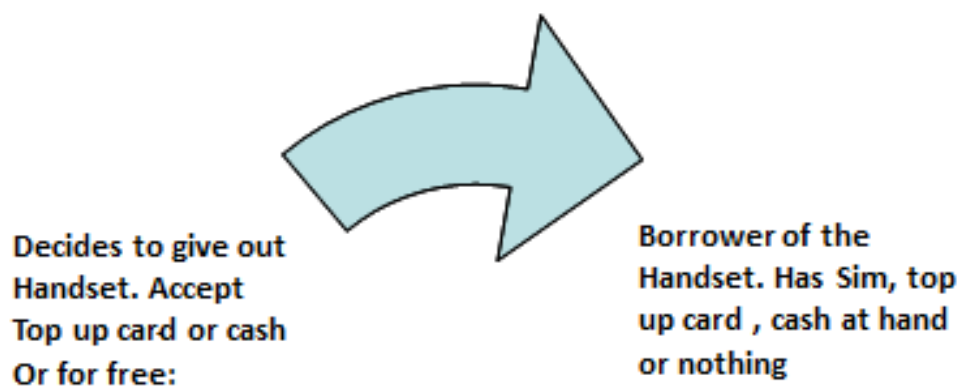

BUT prerequisites are they are

given for trust, or family relations

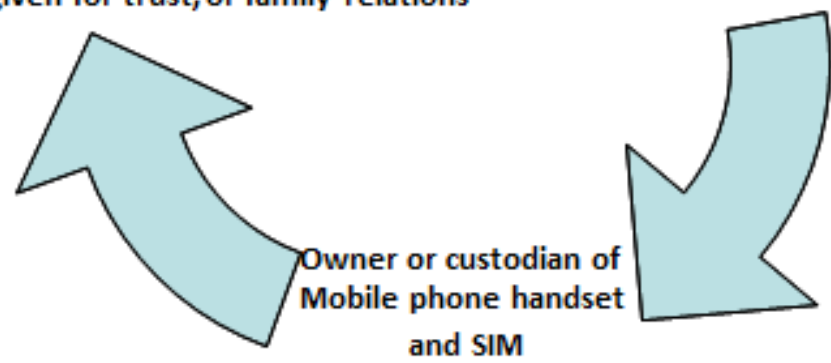

Mobile phone sharing patterns in Marakwet (ethnographic data, 2011)

Most participants shared their mobile phones for free across the divides of age, gender and economic status. The study showed that sharing was largely altruistic, as opposed to a means of addressing a lack of money or resources. However, data also revealed that altruistic acts can be motivated by a lack of resources, a position illustrated by Chebeet, a 38 year old woman: 
Volume 1, Issue 1: New Directions in Media Research 2015

People don't share mobile phone just because they don't have enough money; sometimes people share mobile because of many reasons, like a poor network from Orange may warrant someone to borrow a phone from someone with Safaricom. Then, again, the issue of charging... if one's phone loses charger he or she will ask to use another's that has a charger. Yeah, it is always like that around here.

Kibiwott, a civil servant aged 42, corroborated Chebeet's position, insisting that it is not only money or a lack of it that encourages sharing:

Sometimes, when people share the phone they get together and can discuss stuff. For example, the other day our member of parliament called on us in a baraza [open air meeting, held under a tree] over the phone, the person put his phone connected to the speakers and we talked with her for over an hour. So she has the money but prefers to share the phone so that she can address the constituents!

Kibiwott's testimony broadens the scope of sharing from the simple need of people for air time to include the sharing of organisation, leadership and the like. This is true of assemblage theory, which posits that assemblages are not permanent but, in fact, temporal, because as components, such as the mobile phone, organisation, or even leadership structures interact new assemblages form. Assemblages speak of connectivity, interrelationships and emergence, as seen in the above testimonies. Mobile telephony thus facilitates more sharing of community life and also reinforces social networks, such as the barazas, seen as important common meeting spaces. Most teenagers used shared mobile phones to share music downloads, news alerts and, in the case of boys, sports reports. To do so, they converged by the hillside where reception was clearer. In this way, mobile telephony functions as a facilitator of further social networks and social connections. This practice reflects Lefebvre's (1991) theory that space production assumes different modes, from natural space to a more complex production of social space.

Besides airtime top-up, another prevalent mobile phone sharing practice is beeping, otherwise known as "flashing" or "please-call-me." This practice involves calling an individual and hanging up even before they can answer. In some cases, this is symbolic. For example, teenage girls indicated that if they flashed their boyfriends twice, it would be to convey that they needed top-up. Otherwise, it meant that the beeper or flasher was expected to be called back.

Usually, such practices connect with the economic status of an individual. The study established that individuals who are flashed are perceived by the "flashers" as being able to call back, since they were perceived to have money or, at least, have more money than the flashers. 
Volume 1, Issue 1: New Directions in Media Research 2015

However, flashing is also used to convey symbolic meanings understood by those engaged in this practice. Emmy, aged 21, noted: 'When I flash [my boyfriend] twice he knows I am asking for air time, but if I flash once, it means he needs to call me back.' Other girls were in agreement with the symbolic meaning of flashing, though views varied individually. Kibet, a 49-year old businessman, stated:

I hardly get flashed but when I am, I first of all feel afraid;, I get scared because I think to myself, "Something must have terribly gone wrong", and when I call, sometimes it is really bad news like someone has died or sometimes good. Mostly it is bad news.

Lena, a mother of two, insisted that:

Flashing is a nice way to hide your shame, at least, imagine if you have a phone that doesn't ring, at least when you flash, someone can call you. Like when my children take too long to call me I flash them, then they call me and I feel good.

However, one of the key challenges of flashing using a shared mobile phone is that it is futile, unless the recipient of the flashing recognises the flasher, though in most cases, however, the "flashers" might have given their number to those they are flashing.

Another common mobile phone sharing practice among teenage boys in Marakwet is 'harambee', a Kiswahili word meaning resource pooling. This is a situation or process, whereby each individual puts his or her money towards paying for mobile phone charging and pre-paid phone credit. The money is credited into one person's phone, and others are invited to text or call or listen to radio, music, news, etc.

Nicodemus, aged 18 , does not own a phone, while Musa, aged 21, does. Together, they agree how much is needed to maintain Musa's phone. In pooling funds for pre-paid top-up cards and charging the phone to be able to sign up for news alert and music downloads, the pair is joined by Boaz, 19, and Kiptoo, 23. Thus, the four do not need individual phones. Instead, they just need to raise enough money to top up Musa's phone. Though the boys are happy that they are able to use and access Musa's phone, they sometimes feel awkward having to go to him to receive or read text messages from their girlfriends. Each of the boys mostly wants to own a phone. These situations illustrate the nature of assemblages: always territorialising and re-territorialisng. For instance, if Musa decided to give them privacy to read texts from their girlfriends, they could feel a sense of privacy and pride, but the fact that those texts could remain in Musa's phone unless deleted is a source of worry too, as the boys revealed. 
Volume 1, Issue 1: New Directions in Media Research 2015

Evidence showed that most personal mobile phones in Marakwet are basically communal. Most respondents said that they shared their handsets with whoever was in need of them in the community, on the condition that the assisted individuals used 'good language', because in some cases they had lent their phones to individuals, who used them to insult people. For this reason, mobile phone owners became more vigilant, choosing to stay close when borrowers used their phones.

The majority of participants affirmed that they would share their handsets for free, especially with old men and women, as they were considered to be custodians of culture. However, a small proportion, mostly young people, would usually charge money for their handsets. They would allow others free access, only if such individuals proved beyond reasonable doubt that they could not afford a top-up card. Just like the older men and women, they would be vigilant and ask that users stayed close, in case anyone decided to be mischievous by using abusive language in calls and texts. Thus, trust was a pre-requisite to phone sharing.

Basically, altruism and reciprocity inform the practice of sharing of resources in Marakwet. A study by Chavan and Gomey (2008) of the cultural factors behind phone sharing in rural India showed that people were largely interested in sharing their devices. Owners and users of mobile phones were happy to share them with a wide range of significant others within their social relationships, such as family, friends, siblings, peers, relatives and even strangers. According to that study, sharing occurred at both private and public locations, even though most times the boundaries between the two spaces were blurred.

\subsection{Trust and mischief assemblages/concerns of mobile phone sharing}

Moral economy is a key feature of Marakwet life. According to Domestication of technology theorists (Silverstone et al., 1992; Moley, 2003; Gray, 1992; Goggin, 2006; DuGay et al., 1997) this term situates values, norms and regulations of behaviour around the household. This is evident in this research, as individuals were expected to behave appropriately when using a shared phone, and not to use it to abuse or insult others, share insensitive text messages, and cheat/con people. To prevent these, phone lenders stayed very close to borrowers, to guard against any transgression.

The act of remaining close to borrowers during phone use was also tied to larger societal expectations and disciplinary measures introduced by Kenya's regulator, Communication Authority of Kenya. Most of the interviewees expressed concern about possible repercussions for them if borrowers used their phones to engage to abuse people or cause mischief, as the government 
Volume 1, Issue 1: New Directions in Media Research 2015

regulator would hold them, rather than the borrowers, responsible, since SIM cards were registered under usernames.

Older participants emphasised the centrality of trust as a consideration for sharing their mobile phones. Chukor, a father of two teenage boys, stated:

You see, in as much as I would want to help everybody, there are people who are very bad. Someone can ask to use your phone to call, text or even send M-Pesa. But when they do like that, they send abusive texts or quarrel with someone using your phone.

However, when asked whether there were situations when trust was not obligatory, he noted as follows:

Well, you cannot refuse someone to use your phone for emergency cases like sicknesses, invasions of the Pokots or even concerning the death of a loved one! When it comes to a matter of life and death, you do not need to be that cautious.

In this scenario, sharing is one of those Marakwet values that do not consider emergency situations as a precondition. But Hezekia, 80 years old, noted with caution:

These days there are many people who are corrupt and bad; they will lie to you and even steal the phone from you, especially for those of us that cannot read or write. So I must know you, know your character and behaviour, before I can allow you to use my phone.

However, he recognised the need for compromise in certain compelling emergency situations:

But when a child is sick or there is an invasion from the Pokots (a warring neighbouring community also a sub tribe of Kalenjin tribe) or an accident, anyone can use my phone because that is a matter of life and death.

Other participants expressed similar sentiments regarding health or emergency situations. In such cases, one would be obliged to share, regardless of whether one knew the borrower, or wished to share or not. For some, this was the only case whereby sharing was done for free, with the borrower choosing to give a tokenistic contribution if they so wished. Apparently, in adverse situations affecting the community, everyone was expected to share freely, whereas in ordinary situations, one had the prerogative to choose. Teens preferred to share with their peers, but were also open to lending to their parents and neighbours or strangers. The elderly, on the other hand, only shared with their grandchildren and wives, aside from the overall sharing that was need-based. The majority 
Volume 1, Issue 1: New Directions in Media Research 2015

of the women used the mobile phone quite often through sharing, even though the majority of phone owners were men.

Mobile phone sharing, therefore, reveals participants' personalities. Farman advances this position, showing a link between spatial relationships and identification. He suggests that "spatial relationships have always been determined in the way we understand ourselves" (Farman, 2012, p. 17). Mobile telephone sharing, in this case, does not only highlight the patterns of communities, but also the ways these practices reproduce themselves in different social settings. As participants' testimonies show, mobile phone sharing also connects with the self-perception of mobile telephony users (see Goffman, 1959).

Mischief was cited as one of the risks of mobile phone sharing, irrespective of the reason for sharing. Siaban, 48 years old, narrated how, due to lack of electricity, he had to take his phone to the nearby corner shop for charging. He explained that, because of this, he had to fight hard to regain his friend's trust:

I took my phone as usual for charging and paid. While my phone was still at the charging shop someone went and said that was his phone and needed to make a call and return it for charging. He was given the phone, after which he sent an abusive text. So when I went to finally take it back from the charger's shop, a friend of mine whose name I had saved called me and rained insults on me, asking me how could I. We had to call Saraficom [leading service operator] to verify what time it was texted and searched among ourselves until we found the culprit. It is very bad. You cannot be too safe with a mobile phone.

Mischief was further cited regarding security matters. Mathew, 58, narrated:

Sometimes mobile phone can cause unnecessary worries, like one day someone send texts around that [a rival sub-tribe] Pokots were coming to attack us...and so people got so tensed up only for a second message to be sent out to friends to say it was a joke. I wish such people could be arrested.

\section{Conclusion}

Though mobile phone sharing is widely embraced and practised, numerous risks accompany it, and any excitement is equalled by concerns about it. This is typical of assemblage perspectives, which display complexities, because as wholes they are composed of heterogeneous components. This paper has challenged the personal use of mobile telephony by showcasing how mobile phone 
Volume 1, Issue 1: New Directions in Media Research 2015

sharing affects the lives of people and that mobile phone sharing is not necessarily due to the paucity of mobile phone devices or the capacity of rural users to afford. In fact, in reality, mobile phone sharing is complex and largely based on the societal duty to share, rather than the simplistic notion that non-sharing is due to lack of money.

This paper has also fronted assemblage theory as a possible theoretical framework for understanding the complex interactions of mobile phone users, mobile phone sharing patterns, with respect to context and the culture of people of Marakwet, to reveal the multifaceted nature of mobile phone appropriation and domestication in rural Kenya. The study also found that mobile phone sharing creates and expands community spaces, such that there is no longer public and private space dichotomy. The paper thus highlighted values, norms and regulations by the government as critical in determining how much of the device is shared. There is a need to do a further investigation on whether or not mobile phone sharing affects or is affected by gender differentiation, power and age. Although the study has shown that mobile phone sharing is gender neutral, there are situations when social networks demand a mobile phone sharing among people of the same gender, age group and literacy levels. Mobile phone sharing therefore, produces systematic exclusions and inclusions and, on other occasions, preferential access.

\section{References}

Burell, J. (2010) 'Evaluating Shared Access: Social equality and the circulation of mobile phones in rural Uganda'. Journal of Computer-mediated Communication, 15, pp. 230-250.

Callon, M. (1991) Techno-economic networks and irreversibility. In L. John (ed.) A sociology of monsters: essays on power, technology and domination (132-165). London: Routledge.

Chavan, A., and Gomey, D.(2008) 'The Dilemma of the shared Mobile Phone: Culture strain and product Design in Emerging economies.' ACM Interactions, 15: 34-39.

Communication Commission of Kenya (2011) Third quarterly sector statistics report. Nairobi: Communications Commission of Kenya.

DeLanda, M. (2006) A New Philosophy of Society: Assemblage Theory and Social Complexity. London: Continuum.

Donner, J. (2005) The Social and economic implications of mobile telephony in Rwanda: an ownership/access typology. In P. Glotz, S. Bertschi and C. Locke (eds.) Thumb Culture: The Meaning of Mobile Phones for Society (37-52). Bielefeld: Trascript Verlag.

Donner, J. (2008) Research approaches to mobile use in the developing world: a review of the literature. The Information Society, 24(3): 140-159. 
Volume 1, Issue 1: New Directions in Media Research 2015

Donner, J., and Steenson, M. (2008) "Beyond the Personal and Private: Modes of Mobile Phone Sharing in Urban India." In edited by S. Campbell and R. Ling (eds.) The Reconstruction of Space and Time: Mobile Communication Practices (231-250). Piscatawy, NJ: Transaction Publishers.

Du Gay, P., Hall, S., Mackay, J.L. and Negus, K. (1997) Doing Cultural Studies: the history of Sony Walkman. London: Sage.

Goffman, E. (1959) The Presentation of Self in Everyday Life. NY: Doubleday.

Goggin, G. (2006) Cell Phone Culture: Mobile Technology in Everyday Life. London: Routledge.

Gray, A. (2003) Research Practice for Cultural Studies. London: Sage.

Hahn, H.P. and Kibora, L. (2008) 'The Domestication of the Mobile Phone: Oral Society and New ICT in Burkina Faso.' Journal of Modern African Studies, 46 (1): 87-109.

Haddon, L. (2006) The Contribution of Domestication Research to In-Home Computing and Media Consumption. The Information Society, 22: 195-203.

Haddon, L. (1992) Explaining ICT Consumption: The case of the home computer. In R. Silverstone and E. Hirsch (eds) Consuming Technologies: Media and Information in Domestic Spaces (82-96). London: Routledge.

Ito, M., Okabe, D. and Matsuda, M. (eds.) (2005) Personal, Portable, Pedestrian: Mobile Phones in Japanese Life. Cambridge, Mass.: MIT Press.

Jack, W. and Suri, T. (2011) Mobile money: The economics of M-PESA. Washington DC: NBER.

Katz, J, \& Aakhus, R. (eds.) (2002) Perpetual Contact: mobile communication, private talk, public performance. Cambridge: CUP.

Latour, B. (2005) Reassembling the Social: An Introduction to Actor-Network-Theory. Oxford: OUP.

Lefebvre, H. (1991) The Production of Space. Oxford: Blackwell.

Ling, R. (2008) New Tech, New Ties: How Mobile Communication is Reshaping Social Cohesion. Cambridge, MA: MIT Press.

Ling, R. (2004) The Mobile Connection: The Cell Phone's Impact on Society. San Francisco: Morgan Kaufman.

Ling, R. (1997) One can talk about common manners!' Use of mobile telephones in inappropriate situations. In L. Haddon (ed.) Communication on the move; experience of mobile telephony in the 1990's. COST Report, Telia, Farsta.

Livingstone, S. (2002) Young People and New Media. London: Sage.

Marcus, G., and Saka, E. (2006) 'Assemblage.' Theory, Culture and Society, 23(2-3): 101-106.

Morley, D (2003) 'What's home got to do with it?' European Journal of Cultural Studies, 6(4): 435458. 
Volume 1, Issue 1: New Directions in Media Research 2015

Plant, S.,(2005) 'On the Mobile. The Effects of Mobile Telephones on Social and Individual Life' http://www.motorola.com/mot/doc/0/234 MotDoc.pdf. Accessed 22/5/2015.

Silverstone, R., Hirsch, E. and Morley, D. (1992) Information and communication technologies and the moral economy of household. In R. Silverstone and E. Hirsch (eds.) Consuming Technologies: Media and Information in Domestic Spaces (15-31). London: Routledge.

Weilemann, A and Larsson, C. (2002) Local use and Sharing of Mobile phones. In B. Brown, N. Green and R. Harper (eds.) Wireless World: social and interaction aspects of the mobile Age (92-107). London: Sage.

\section{Biography}

Leah Jerop Komen PhD is currently a lecturer at Daystar university-Kenya. She has a master's degree in Development Communication from Daystar University, and a PhD from University of East London. Her research interests include: the domestication of communication technologies in sub-Saharan Africa and how human-technology and context interrelationships from part of social assemblages that intersect with development. 
Contact author(s):

ledavid2002@gmail.com

\section{Contact for(e)dialogue}

General inquiries at foredialogue@leicester.ac.uk

Editorial inquiries at foreditorial@leicester.ac.uk 